\title{
Relationships Between Vitamin D Status and PTH over 5 Years After Roux-en-Y Gastric Bypass: a Longitudinal Cohort Study
}

\author{
Stephen Hewitt ${ }^{1,2}$. Jon Kristinsson ${ }^{1,3}$. Erlend Tuseth Aasheim ${ }^{1,4}$. Ingvild Kristine Blom-Høgestøl ${ }^{1,2}$ • Eirik Aaseth ${ }^{5}$. \\ Jørgen Jahnsen ${ }^{2,6} \cdot$ Erik Fink Eriksen ${ }^{1,2} \cdot$ Tom Mala $^{1,3}$
}

Published online: 18 April 2020

(C) The Author(s) 2020

\begin{abstract}
Purpose Secondary hyperparathyroidism (SHPT) after obesity surgery may affect bone health. Optimal vitamin D levels have not been established to prevent SHPT postoperatively. We investigated whether SHPT differed across threshold levels of serum 25-hydroxyvitamin D (S-25(OH)D) from 6 months up to 5 years after Roux-en-Y gastric bypass (RYGB).

Materials and Methods We included 554 patients at follow-up 5 years postoperatively. Blood samples were analysed for $\mathrm{S}-25(\mathrm{OH}) \mathrm{D}$, ionized calcium (iCa) and parathyroid hormone (PTH) during follow-up.

Results PTH and prevalence of SHPT increased from 6 months to 5 years postoperatively, while S-25(OH)D and iCa decreased (all $P<0.001)$. PTH and SHPT development are related with S-25(OH)D, and PTH differed between all subgroups of S-25(OH)D. SHPT occurred less frequently across all subgroups of S-25(OH)D $\geq 50 \mathrm{nmol} / 1$ during follow-up: odds ratio (OR) 0.44 (95\% CI $0.36-0.54)$ in patients with $\mathrm{S}-25(\mathrm{OH}) \mathrm{D} \geq 50 \mathrm{nmol} / \mathrm{l}, \mathrm{OR} 0.38(0.30-0.49)$ with $\mathrm{S}-25(\mathrm{OH}) \mathrm{D} \geq 75 \mathrm{nmol} / \mathrm{l}$ and OR $0.19(0.12-0.31)$ with S-25(OH) D $\geq 100 \mathrm{nmol} / 1$, all compared with S-25(OH)D $<50$ nmol/1. At 5 years, 208/554 patients $(38 \%)$ had SHPT; SHPT was found in 94/188 patients $(50 \%)$ with S-25(OH)D $<50$ nmol/1, in $69 / 222(31 \%)$ with S-25(OH)D 50-74 nmol/1, in 40/117 (34\%) with S-25(OH)D 75-99 nmol/1 and in 5/27 (19\%) with S-25(OH)D $\geq 100 \mathrm{nmol} / 1$. An interaction existed between S-25(OH)D and iCa. Bone alkaline phosphatase remained increased with SHPT.

Conclusions A significant relationship existed between S-25(OH)D and development of PTH and SHPT. The prevalence of SHPT was lower with threshold levels $25(\mathrm{OH}) \mathrm{D} \geq 50 \mathrm{nmol} / \mathrm{l}$ and $\geq 75 \mathrm{nmol} / \mathrm{l}$ over the 5 years, and lowest with $\mathrm{S}-25(\mathrm{OH}) \mathrm{D} \geq$ $100 \mathrm{nmol} / \mathrm{l}$.
\end{abstract}

Keywords Bariatric surgery $\cdot$ Morbid obesity $\cdot$ Vitamin D $\cdot$ Calcium $\cdot$ Parathyroid hormone $\cdot$ Bone turnover

\section{Electronic supplementary material The online version of this article (https://doi.org/10.1007/s11695-020-04582-5) contains supplementary material, which is available to authorized users.}

Stephen Hewitt

stehewi@online.no

Jon Kristinsson

joakri@ous-hf.no

Erlend Tuseth Aasheim

erlend.aasheim@gmail.com

Ingvild Kristine Blom-Høgestøl

ingvild.hogestol@gmail.com

Eirik Aaseth

eirik.aaseth@sykehuset-innlandet.no

Jørgen Jahnsen

jorgen.jahnsen@medisin.uio.no

Erik Fink Eriksen

efinkeriksen@gmail.com
Tom Mala

tommenmala@gmail.com

1 Department of Endocrinology, Morbid Obesity and Preventive Medicine, Oslo University Hospital HF, Aker, P.O. Box 4950 Nydalen, 0424 Oslo, Norway

2 Institute of Clinical Medicine, University of Oslo, 0450 Oslo, Norway

3 Department of Gastrointestinal Surgery, Oslo University Hospital, P.O. Box 4950, Nydalen, 0407 Oslo, Norway

4 Department of Global Health and Documentation, Norwegian Directorate of Health, P.O. Box 220, Skøyen, 0213 Oslo, Norway

5 Department of Medicine, Innlandet Hospital Trust, Elverum, Norway

6 Department of Gastroenterology, Akershus University Hospital, 1474 Lørenskog, Norway 


\section{Introduction}

Obesity surgery provides effective weight loss in morbid obesity $[1,2]$. Changes in gastrointestinal anatomy and physiology may also influence intestinal uptake and nutritional status, including for calcium and vitamin D [1-6]. Calcium and vitamin D are central in parathyroid hormone $(\mathrm{PTH})$ regulation $[7$, 8]. Frequently, PTH is elevated after obesity surgery, and long-term studies indicate that PTH increases over time [4, 9-15].

Relationships of calcium and vitamin D with PTH should be explored further, as PTH may impact bone turnover and bone mineral density (BMD) postoperatively [14-24]. More focus on these are needed during follow-up. Supplementation of calcium and vitamin D is recommended after obesity surgery, but secondary hyperparathyroidism (SHPT) remains prevalent $[22,25]$. Few studies have shown differences in prevalence of SHPT with 25-hydroxyvitamin D (S-25(OH)D) threshold levels higher than $\geq 50 \mathrm{nmol} / 1$ after obesity surgery $[9,20]$. It could be that optimal vitamin D should be higher after obesity surgery than in other nonsurgical populations $[7,8,24,26]$.

We aimed to study the development of PTH and SHPT over 5 years after Roux-en-Y gastric bypass (RYGB), and relationships between these and different threshold levels of $\mathrm{S}-25(\mathrm{OH}) \mathrm{D} \geq 50 \mathrm{nmol} / \mathrm{l}$. We assessed whether the prevalence of SHPT would be lower among patients with higher $\mathrm{S}-25(\mathrm{OH}) \mathrm{D}$ up to 5 years postoperatively.

\section{Materials and Methods}

\section{Patients and Study Design}

This longitudinal observational cohort study was analysed prospectively, and the report was written to comply with the STROBE checklist [27].

Morbid obesity was defined as BMI $\geq 40 \mathrm{~kg} / \mathrm{m}^{2}$, or BMI $\geq$ $35 \mathrm{~kg} / \mathrm{m}^{2}$ with obesity-related comorbidities [28]. Obesity surgery was offered at Oslo University Hospital, Aker, after failed weight loss by other means. Laparoscopic RYGB was the preferred procedure in the period, with construction of a gastric pouch $25-30 \mathrm{ml}$, a $150-\mathrm{cm}$ antegastric, antecolic alimentary limb and a 50-cm biliopancreatic limb $[29,30]$.

We aimed for minimum 500 patients in a population with high follow-up. Candidates were RYGB patients operated 2004-2009. They were evaluated preoperatively and postoperatively with weight, height and blood samples. Follow-up visits were after 6 weeks, 6 months, 1 year, 2 years, 3-4 years and 5 years. At 5 years, all were contacted by letter and eventually by telephone. Body weight was measured electronically (platform weight, Seca 635 0-300 kg, class III), height with wall-fixed steel measure and blood samples were drawn after overnight fast.

Patients with signed consent and valid PTH and S-25(OH)D at 5 years were candidates, while patients with primary hyperparathyroidism and elevated creatinine were excluded.

\section{Laboratory Analyses}

Serum intact PTH (1-84), S-25(OH)D, ionized calcium (iCa) and bone specific alkaline phosphatase (B-ALP) were determined at the Hormone Laboratory, Oslo University Hospital, Aker. PTH was analysed by a chemiluminoimmunometric assay (Immulite 2000/2500, Siemens Health Care Diagnostics) (reference range 1.5-7.0 pmol/1, coefficient of variation $(\mathrm{CV}) 7 \%)$. S-25(OH)D was determined by radioimmunoassay (Dia-Sorin) (reference range 37-131 nmol/l, CV 14\%), from September 2012 with liquid chromatographymass spectrometry (LC-MS/MS) (identical reference range, CV 9\%); measurements were comparable. Different methods were used for iCa: first, (a) CIBA Corning, instrument 634 $\mathrm{Ca}^{2+} / \mathrm{pH}$ Analyser (Bayer); from December 2005 to December 2007, (b) Rapidlab 348 pH/Blood Gas Analyser (Instru-Med) (both reference range 1.15-1.35 mmol/l, CV $1 \%$ and $2 \%$, respectively); from January 2008 to January 2012, (c) Rapidlab 348 pH/Blood Gas Analyser (InstruMed) (reference range $1.18-1.35 \mathrm{mmol} / \mathrm{l}$ ); from February 2012, (d) Cobas b221 (Roche Diagnostics) (reference range 1.15-1.33 mmol/l, CV 2\%). Reference for iCa was (c) with reference range $1.18-1.35 \mathrm{mmol} / \mathrm{l}$. Values from (a) and (b) were transformed to (c) adding $0.015 \mathrm{mmol} / \mathrm{l}$ (differences between reference ranges). Similarly were values from (d) transformed to (c) adding $0.025 \mathrm{mmol} / \mathrm{l}$. B-ALP was determined enzymatically after immune-extraction (Metra Biosystems) (reference range: women 12-31 U/1, men 15-41 U/l (CV $12 \%)$. Standard analyses included S-25(OH)D, iCa and PTH during follow-up, which were analysed sporadically preoperatively. Phosphate, magnesium, creatinine and total alkaline phosphatase (ALP) in plasma were analysed at the Central Laboratory, Oslo University Hospital, Aker, with a Modular (Roche) analyzer: Phosphate and magnesium were determined photometrically, creatinine enzymatically and ALP by an enzymatic calorimetric measurement.

\section{Definitions and Subgroups}

SHPT was defined as PTH $>7.0 \mathrm{pmol} / 1$ with no elevation of iCa (i.e. $\leq 1.35 \mathrm{mmol} / \mathrm{l})$. S-25(OH)D was grouped into 4 categories, $<50,50-74,75-99$ and $\geq 100 \mathrm{nmol} / 1 . \mathrm{S}-25(\mathrm{OH}) \mathrm{D}<$ $50 \mathrm{nmol} / 1$ is commonly acknowledged as vitamin D deficiency (or insufficiency) [7, 8]. Calcium levels were grouped into 3 by normal reference range (iCa $\leq 1.23,1.24-1.29$, $\geq$ $1.30 \mathrm{mmol} / \mathrm{l}$ ); all $\mathrm{iCa}$ values $\leq 1.23 \mathrm{mmol} / \mathrm{l}$ are termed in the 
"lower range". Values below normal reference range $(<1.18 \mathrm{mmol} / \mathrm{l})$ are termed "Low iCa".

\section{Supplementation}

Recommended daily supplements included one multivitamin (cholecalciferol 200 IU) and two combination tablets, each containing calcium carbonate $500 \mathrm{mg}$ and cholecalciferol 400 IU. Compliance was defined by use of calcium $\geq$ $500 \mathrm{mg}$ and vitamin $\mathrm{D} \geq 600 \mathrm{IU}$ minimum 5 days a week, noncompliance as less or no use. Supplements were adjusted to keep blood values within normal reference range, from 2012 to maintain $\mathrm{S}-25(\mathrm{OH}) \mathrm{D} \geq 50 \mathrm{mmol} / \mathrm{l}$, or $\mathrm{S}-25(\mathrm{OH}) \mathrm{D} \geq$ $75 \mathrm{nmol} / 1$ in cases with SHPT [7, 8]. Our supplementation regimen also included oral iron (100 $\mathrm{mg}$ daily) and intramuscular vitamin B12 injections (1 mg per 3 months).

\section{Statistical Analyses}

Statistical analyses were performed with IBM SPSS for Windows, version 25. Continuous and categorical variables were tested with $t$ test and chi-square test as appropriate. Regression analyses were performed with linear mixed model, diagonal covariance matrices for PTH and B-ALP using individual repeated measurements, time-dependent covariates and random intercept. Variables were included in multivariate analyses of PTH with stepwise backward elimination of nonsignificant variables. Gender, age and BMI were included as covariates. We tested multiplicative interactions for $\mathrm{S}-25(\mathrm{OH}) \mathrm{D}, \mathrm{iCa}$ and time on PTH, and PTH and time on BALP. B-ALP was adjusted for gender. Generalized estimating equations (GEE), unstructured covariance matrices were used for SHPT. Missing data were not imputed. We analysed two periods: from baseline to 6 months postoperatively and from 6 months to 5 years. The second period was the main focus, as $\mathrm{S}-25(\mathrm{OH}) \mathrm{D}$ and PTH were routinely assessed. Continuous variables are presented with means and standard deviations $( \pm \mathrm{SD})$, categorical variables in percentages, and odds ratios (OR) and relative ratios (RR) with $95 \%$ confidence intervals $(95 \% \mathrm{CI})$.

\section{Results}

Of 823 operated, $584(71 \%)$ attended 5-year follow-up. Included were 554 patients $(67 \%)$, after exclusion of 4 with no signed consent, 10 with a suspicious primary hyperparathyroidism, 3 with elevated creatinine, and 13 with missing data of S-25(OH)D and PTH at 5 years. Follow-up period was $5.3 \pm 0.4$ years. Three patients had moved from our region and could not be contacted, and 7 had died during the 5 years. Table 1 summarizes preoperative characteristics.
Table 1 Preoperative characteristics $(N=554)$

\begin{tabular}{llll}
\hline & $N$ & Mean & SD \\
\hline Women & 384 & & \\
Age $(\mathrm{y})$ & 554 & 41.7 & 9.1 \\
Weight $(\mathrm{kg})$ & 554 & 136 & 22 \\
Height $(\mathrm{cm})$ & 554 & 172 & 10 \\
BMI $\left(\mathrm{kg} / \mathrm{m}^{2}\right)$ & 554 & 46.2 & 5.3 \\
Blood samples & & & \\
PTH (pmol/l) & 160 & 6.4 & 2.8 \\
S-25(OH)D (nmol/l) & 158 & 53 & 22 \\
iCa (mmol/l) & 245 & 1.25 & 0.04 \\
Phosphate $(\mathrm{mmol} / \mathrm{l})$ & 204 & 1.02 & 0.19 \\
Magnesium $(\mathrm{mmol} / \mathrm{l})$ & 247 & 0.81 & 0.07 \\
Creatinine $(\mu \mathrm{mol} / \mathrm{l})$ & 549 & 68 & 13 \\
B-ALP $(\mathrm{U} / \mathrm{l})$ & 44 & 26.3 & 6.6 \\
SHPT & 56 & $(35 \%)$ & \\
\hline
\end{tabular}

$B M I$, body mass index; $P T H$, parathyroid hormone; $S-25(O H) D$, serum 25-hydroxyvitamin $\mathrm{D} ; i C a$, ionized calcium; $B-A L P$, bone alkaline phosphatase; $S H P T$, secondary hyperparathyroidism

\section{The First 6 Months}

BMI decreased $27 \%$ in the first 6 months from $46.2 \pm 5.3$ to $33.8 \pm 5.1 \mathrm{~kg} / \mathrm{m}^{2}$, PTH decreased from $6.4 \pm 2.8$ to $5.2 \pm$ $2.5 \mathrm{pmol} / 1$ and prevalence of SHPT from 35 to $18 \%$ (all $P<0.001)$ S $-25(\mathrm{OH}) \mathrm{D}$ and iCa were independently related with PTH development $(P<0.001)$.

PTH decreased in all subgroups of S-25(OH)D. Patients with $\mathrm{S}-25(\mathrm{OH}) \mathrm{D}<50 \mathrm{nmol} / 1$ had highest PTH preoperatively and 6 months postoperatively, and they had the largest decrease in PTH $(P<0.001)$. PTH related positively with B-ALP $(P<0.001)$.

\section{Six Months to 5 Years Postoperatively}

Figure 1 illustrates development of PTH and SHPT from 6 months to 5 years postoperatively. PTH increased to $6.8 \pm$ $3.5 \mathrm{pmol} / 1$, and the prevalence of SHPT increased to $38 \%$, while S-25(OH)D decreased to $59 \pm 24 \mathrm{nmol} / 1$, and $\mathrm{iCa}$ to $1.22 \pm 0.04 \mathrm{mmol} / \mathrm{l}$ (all $P<0.001)$. BMI increased to $34.5 \pm$ $6.2 \mathrm{~kg} / \mathrm{m}^{2}(P=0.005)$.

\section{Vitamin D, PTH and SHPT}

S-25(OH)D was inversely related with development of PTH and occurrence of SHPT from 6 months to 5 years $(\mathrm{P}<0.001)$, and PTH differed between all subgroups of S-25(OH)D $(\mathrm{P}<$ 0.001) (Fig. 1). Mean PTH response by change in vitamin D levels was.

$\Delta \mathrm{PTH}(\mathrm{pmol} / \mathrm{I})=-0.031 * \Delta 25(\mathrm{OH}) \mathrm{D}(\mathrm{nmol} / \mathrm{I})$ 
Fig. 1 Observed development of parathyroid hormone (PTH) and secondary hyperparathyroidism (\%) from 6 months to 5 years after Roux-en-Y gastric bypass $(N=554)$ to the left, and for subgroups of 25-hydroxyvitamin $\mathrm{D}(\mathrm{S}-25(\mathrm{OH}) \mathrm{D})$ to the right
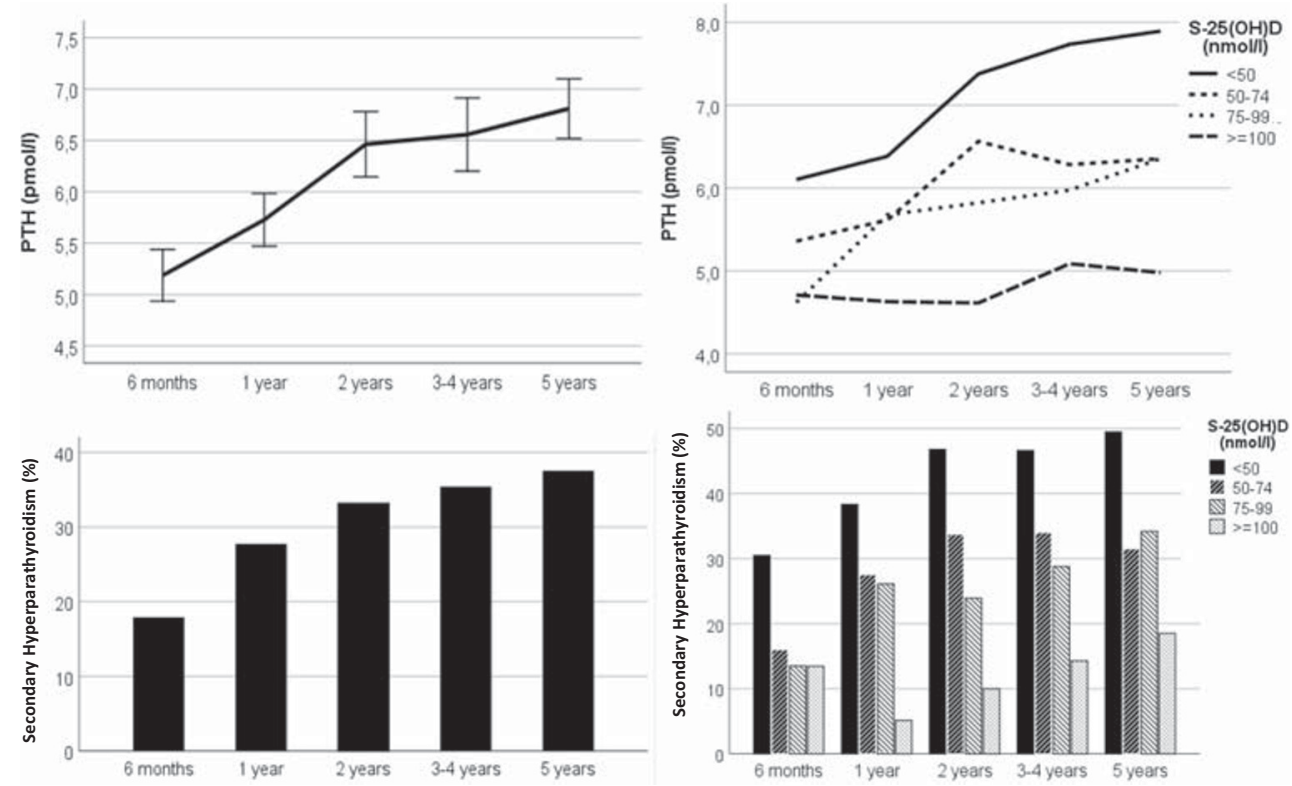

expressing that each $1 \mathrm{nmol} / 1$ increase in S-25(OH)D related with a PTH decrease of $0.031 \mathrm{pmol} / 1$ during follow-up, and vice versa. From 6 months, PTH and prevalence of SHPT increased most with $\mathrm{S}-25(\mathrm{OH}) \mathrm{D}<50 \mathrm{nmol} / \mathrm{l}(\mathrm{P}<0.001)$, but not significantly with $\mathrm{S}-25(\mathrm{OH}) \mathrm{D} \geq 100 \mathrm{nmol} / \mathrm{l}$.

Over the 5 years, SHPT differed between subgroups of S-25(OH)D (Fig. 2). Higher S-25(OH)D levels were associated with lower occurrence of SHPT: OR $0.44(0.36-0.54)$ with $\mathrm{S}-25(\mathrm{OH}) \mathrm{D} \geq 50 \mathrm{nmol} / 1$, OR $0.38(0.30-0.49)$ with $\mathrm{S}-25(\mathrm{OH}) \mathrm{D} \geq 75 \mathrm{nmol} / 1$, OR $0.19(0.12-0.31)$ with $\mathrm{S}-25(\mathrm{OH}) \mathrm{D} \geq 100 \mathrm{nmol} / \mathrm{l}$, all compared with $\mathrm{S}-25(\mathrm{OH}) \mathrm{D}<$
50 nmol/l. Compared with S-25(OH)D 50-99 nmol/1, OR was $0.40(0.26-0.62)$ with $\mathrm{S}-25(\mathrm{OH}) \mathrm{D} \geq 100 \mathrm{nmol} / \mathrm{l}$.

At 5 years, 208 of 554 patients $(38 \%)$ had SHPT. The prevalence was $50 \%$ with $\mathrm{S}-25(\mathrm{OH}) \mathrm{D}<50 \mathrm{nmol} / \mathrm{l}$ (Fig. 3/ Table 2); $61 \%$ with $\mathrm{S}-25(\mathrm{OH}) \mathrm{D}<25 \mathrm{nmol} / \mathrm{l}$. SHPT was less frequent with $\mathrm{S}-25(\mathrm{OH}) \mathrm{D} \geq 50 \mathrm{nmol} / \mathrm{l}(31 \%$, RR 0.63 $(0.51-0.77)), \mathrm{S}-25(\mathrm{OH}) \mathrm{D} \geq 75 \mathrm{nmol} / 1$ (31\%, RR 0.63 $(0.47-0.83))$, and lowest with $\mathrm{S}-25(\mathrm{OH}) \mathrm{D} \geq 100 \mathrm{nmol} / 1$ (19\%, RR $0.37(0.17-0.83))$, all compared with $\mathrm{S}-25(\mathrm{OH}) \mathrm{D}<50 \mathrm{nmol} / \mathrm{l}$. Compared with S-25(OH)D 50$99 \mathrm{nmol} / 1$, PTH was lower with $\mathrm{S}-25(\mathrm{OH}) \mathrm{D} \geq 100 \mathrm{nmol} / 1$
Fig. 2 Odds ratio (OR) for secondary hyperparathyroidism (SHPT) from 6 months to 5 years postoperatively in 554 Roux-en$\mathrm{Y}$ gastric bypass patients by categories of serum 25-

hydroxyvitamin D $(\mathrm{S}-25(\mathrm{OH}) \mathrm{D}$, $\mathrm{nmol} / \mathrm{l}$ ) and ionized calcium (iCa, $\mathrm{mmol} / \mathrm{l}$ ) compared with reference (ref.). S-25(OH)D was adjusted for time (y): OR 1.11 (1.02-1.22), with additional adjustments for baseline $\mathrm{S}-25(\mathrm{OH}) \mathrm{D}$ and $\mathrm{iCa}$ as given
OR for SHPT $6 m$ - 5y postop

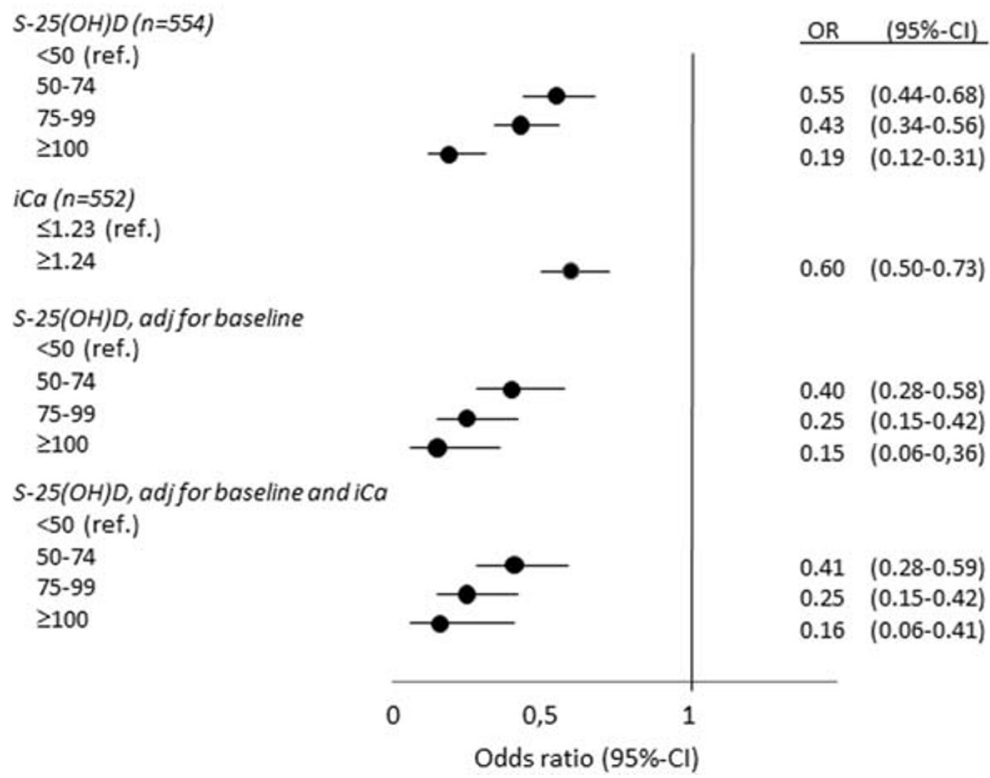


Fig. 3 Relative ratio (RR) for secondary hyperparathyroidism (SHPT) 5 years after Roux-en-Y gastric bypass $(N=554)$ by categories of serum 25 -

hydroxyvitamin D (S-25(OH)D or $\mathrm{D}, \mathrm{nmol} / \mathrm{l}$ ) and ionized calcium (iCa, mmol/l) compared with reference (ref.)
RR for SHPT 5y postop

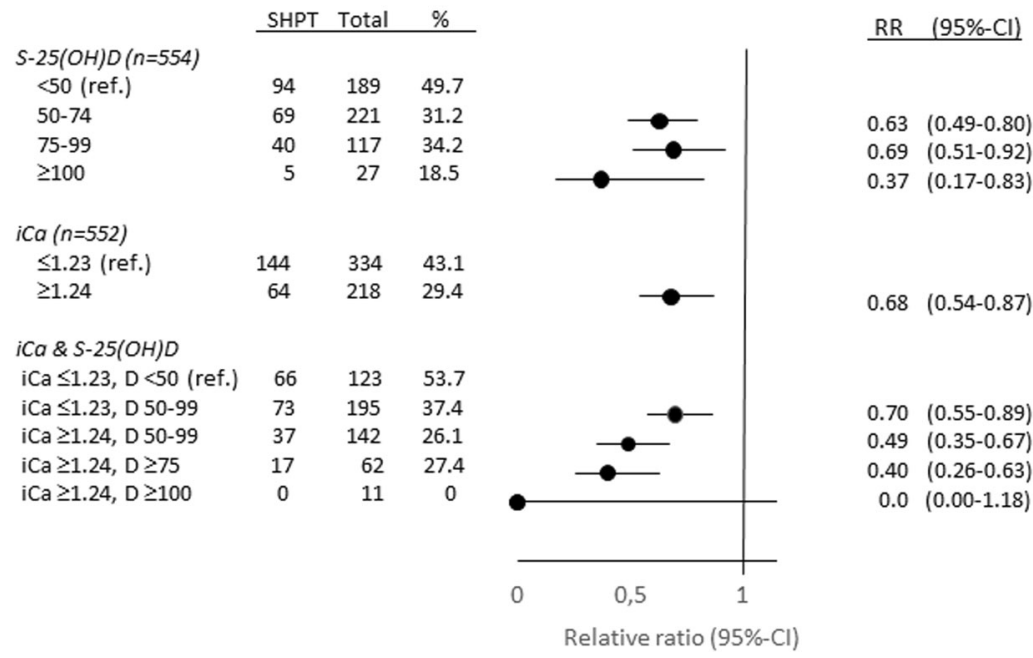

with $\mathrm{S}-25(\mathrm{OH}) \mathrm{D} \geq 100 \mathrm{nmol} / \mathrm{l}$ and $\mathrm{iCa}$ above the lower range (Fig. 3).

\section{Multivariate Analyses}

In multivariate analyses of PTH from 6 months to 5 years (Table 3), the relationship with $\mathrm{S}-25(\mathrm{OH}) \mathrm{D}$ and $\mathrm{iCa}$ remained robust, also with BMI. Interactions for $\mathrm{S}-25(\mathrm{OH}) \mathrm{D}$ and $\mathrm{iCa}$ with time over the 5 years were not significant in multivariate analyses. SHPT occurred more often in men, with lower age and with higher BMI over the period (Supplementary Table). The trend of lower OR with higher S-25(OH)D remained across strata of gender, age and BMI.

\section{Supplementation, PTH/SHPT and Bone Turnover}

360 of $475(77 \%)$ used supplements of calcium and vitamin D at 6 months, and $278(50 \%)$ at 5 years. S-25(OH)D was higher

Table 2 Observed numbers with secondary hyperparathyroidism by vitamin D status at follow-up from 6 months to 5 years after Roux-en-Y gastric bypass $(N=554)$

\begin{tabular}{|c|c|c|c|c|c|c|c|c|c|c|}
\hline & \multicolumn{2}{|c|}{6 months } & \multicolumn{2}{|l|}{1 year } & \multicolumn{2}{|c|}{2 years } & \multicolumn{2}{|c|}{ 3-4 years } & \multicolumn{2}{|l|}{5 years } \\
\hline & SHPT & All & SHPT & All & SHPT & All & SHPT & All & SHPT & All \\
\hline \multicolumn{11}{|c|}{$\mathrm{S}-25(\mathrm{OH}) \mathrm{D}$} \\
\hline$<50$ & 25 & 77 & 38 & 100 & 57 & 121 & 39 & 86 & 94 & 188 \\
\hline $50-74$ & 20 & 125 & 49 & 178 & 57 & 171 & 50 & 147 & 69 & 222 \\
\hline $75-99$ & 17 & 126 & 35 & 134 & 28 & 117 & 20 & 72 & 40 & 117 \\
\hline$\geq 100$ & 6 & 51 & 2 & 39 & 3 & 30 & 2 & 14 & 5 & 27 \\
\hline All & 68 & 379 & 124 & 451 & 145 & 439 & 111 & 319 & 208 & 554 \\
\hline Missing & & 175 & & 103 & & 115 & & 235 & & 0 \\
\hline
\end{tabular}

S-25(OH)D, serum 25-hydroxyvitamin D; SHPT, secondary hyperparathyroidism; All, attenders 
Fig. 4 Observed development of ionized calcium by subgroups of 25-hydroxyvitamin D

$(\mathrm{S}-25(\mathrm{OH}) \mathrm{D})$, and proportions of low calcium and calcium within the lower range from 6 months to 5 years after Roux-en-Y gastric bypass $(N=552)$ (upper), and development of parathyroid hormone $(\mathrm{PTH})$ and proportion with secondary hyperparathyroidism by subgroups of ionized calcium (lower)
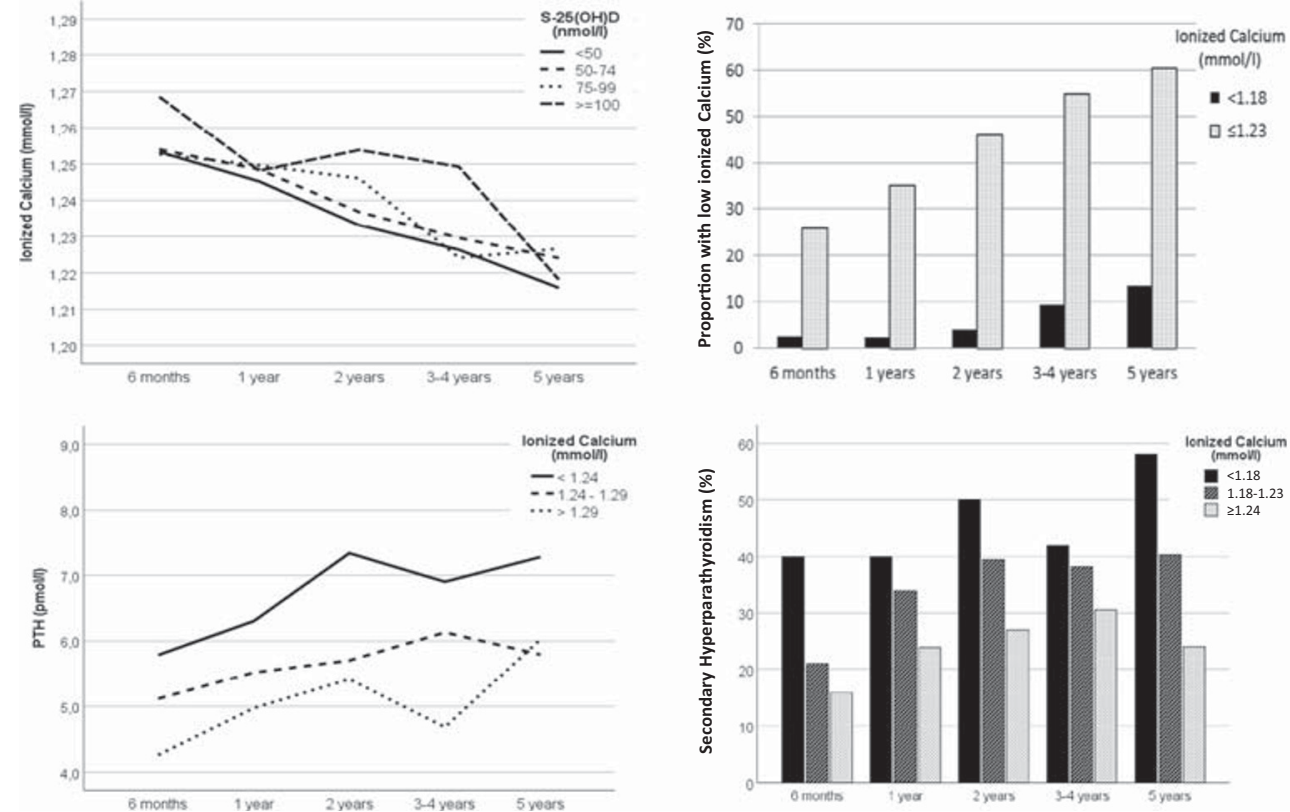

Table 3 Regression analysis ${ }^{\mathrm{a}}$ of parathyroid hormone and modulating factors from 6 months to 5 years after Roux-en-Y gastric bypass $(N=554)$

\begin{tabular}{|c|c|c|c|}
\hline & $B$ & SE & $P$ \\
\hline \multicolumn{4}{|l|}{ Univariate } \\
\hline $\mathrm{S}-25(\mathrm{OH}) \mathrm{D}$ & -0.032 & 0.0025 & $<0.001$ \\
\hline $\mathrm{iCa}$ & -23.9 & 1.46 & $<0.001$ \\
\hline BMI & 0.12 & 0.014 & $<0.001$ \\
\hline Phosphate & -3.57 & 0.38 & $<0.001$ \\
\hline Magnesium & -0.12 & 0.031 & 0.69 \\
\hline Creatinine & 0.023 & 0.0075 & 0.003 \\
\hline Time & 0.32 & 0.028 & $<0.001$ \\
\hline Preop Vit D & -0.034 & 0.0091 & $<0.001$ \\
\hline Gender $^{\mathrm{b}}$ & 0.35 & 0.23 & 0.13 \\
\hline $\mathrm{Age}^{\mathrm{c}}$ & -0.0069 & 0.012 & 0.56 \\
\hline \multicolumn{4}{|l|}{ Multivariate $^{\mathrm{d}}$} \\
\hline I & 42.2 & 4.86 & $<0.001$ \\
\hline $\mathrm{S}-25(\mathrm{OH}) \mathrm{D}$ & -0.248 & 0.064 & $<0.001$ \\
\hline $\mathrm{iCa}$ & -30.65 & 3.81 & $<0.001$ \\
\hline BMI & 0.065 & 0.014 & $<0.001$ \\
\hline $\mathrm{S}-25(\mathrm{OH}) \mathrm{D} \times \mathrm{iCa}$ & 0.182 & 0.051 & $<0.001$ \\
\hline Creatinine & 0.020 & 0.0076 & 0.009 \\
\hline Time & 0.073 & 0.030 & 0.015 \\
\hline
\end{tabular}

${ }^{\mathrm{a}}$ Linear mixed model; ${ }^{\mathrm{b}}$ men 1 , women $0 ;{ }^{\mathrm{c}}$ Age at 5 years; ${ }^{\mathrm{d}}$ Adjusted for age and gender; $\times$, interaction

$R Y G B$, Roux-en-Y gastric bypass; $I$, intercept; $B$, regression coefficient; $S E$, standard error; $S-25(O H) D$, serum 25 -hydroxyvitamin D (nmol/l); $i C a$, ionized calcium (mmol/l); BMI, body mass index $\left(\mathrm{kg} / \mathrm{m}^{2}\right)$;

Creatinine $(\mu \mathrm{mol} / \mathrm{l})$; Time, time postoperatively (years); Preop Vit D, $\mathrm{S}-25(\mathrm{OH}) \mathrm{D}$ preoperatively and PTH lower in users over the period $(P<0.001)$, but not significantly at 5 years.

PTH related positively with B-ALP and ALP over the 5 years $(\mathrm{P}<0.001)$, with interaction for $\mathrm{PTH}$ and time. B-ALP declined by $1.3 \mathrm{U} / 1$ per year, but remained increased with SHPT ( $P<0.001$ for group difference). Total ALP declined slower with SHPT $(P=0.004)$.

\section{Discussion}

PTH and the prevalence of SHPT decreased the first 6 months after RYGB, and thereafter increased up to 5 years. S-25(OH)D was related with PTH development. Patients with vitamin D deficiency had the largest increase in PTH from 6 months, while patients with high $\mathrm{S}-25(\mathrm{OH}) \mathrm{D} \geq 100 \mathrm{nmol} / 1$ had lowest PTH and prevalence of SHPT.

\section{Vitamin D and SHPT}

This study is among few longitudinal long-term reports of SHPT by vitamin D and calcium status after RYGB. Vitamin D deficiency is usually defined by $\mathrm{S}-25(\mathrm{OH}) \mathrm{D}<$ $30-50 \mathrm{nmol} / 1$, while target levels of S-25(OH)D $\geq 50$ $75 \mathrm{nmol} / 1$ are adopted in most recommendations after obesity surgery [1, 2, 4-8]. However, evidence supporting these target levels is limited $[22,24]$.

The observed increase in PTH from 6 months is in accordance with other long-term evaluations [9-13]. S-25(OH)D was strongly related with PTH over time, however, with limited differences in SHPT by traditional target thresholds, 
defined by $\mathrm{S}-25(\mathrm{OH}) \mathrm{D} \geq 50 \mathrm{nmol} / 1$ and $\geq 75 \mathrm{nmol} / \mathrm{l}$. The findings with $\mathrm{S}-25(\mathrm{OH}) \mathrm{D} \geq 100 \mathrm{nmol} / \mathrm{l}$ corresponded with our cross-sectional study 2 years postoperatively [20].

\section{Calcium and SHPT}

Calcium absorption seems reduced after RYGB [31, 32]. However, few have reported a relationship between calcium and PTH $[18,20,23]$. Extracellular calcium is a determinant of PTH secretion, and even calcium within the lower normal range may increase PTH $[20,33,34]$. With the feedback mechanisms involved, PTH may increase above reference range, while serum calcium still remains within normal reference range.

Our observations suggest a role of iCa on PTH. The proportion of patients with $\mathrm{iCa}$ in the lower range increased over time, and $\mathrm{iCa}$ was related with PTH development. This relationship was independent of S-25(OH)D. An interaction existed between S-25(OH)D and iCa on PTH. Still, iCa declined in all subgroups of S-25(OH)D but more slowly with higher levels.

\section{Supplementation, SHPT and Bone Effects}

Several studies have failed to document benefits of vitamin D and calcium supplementation, and the regimens have been questioned $[22,24]$. This study supports a modest effect with supplements of calcium $\geq 500 \mathrm{mg}$ and vitamin $\mathrm{D} \geq 600 \mathrm{IU}$ on PTH. These doses are however lower than recommended by many $[2,4,6]$.

We also found higher B-ALP in patients with SHPT up to 5 years postoperatively, suggesting higher bone turnover. SHPT might therefore help explain increased bone turnover, which is observed up to 5 years after RYGB [18, 19, 22]. SHPT may also lead to reduced BMD, which is observed after weight stabilizes 1-2 years postoperatively $[15,19]$. We recently found SHPT related with lower BMD 10 years after RYGB [21].

\section{Implications}

In clinical practice, SHPT may be considered as a marker of vitamin $\mathrm{D}$ and calcium insufficiency, and it is of concern after RYGB. Further research should address whether increasing S-25(OH)D levels can suppress SHPT and improve bone health. Higher doses seem necessary to achieve sufficient vitamin D levels and suppress SHPT after RYGB [2, 4, 24, 35].

Attention to calcium status seems relevant to identify risk for SHPT. SHPT was more frequent with $\mathrm{iCa}$ in the lower range. Higher S-25(OH)D can increase calcium levels and lower PTH, and some individuals may need higher vitamin D levels than others $[20,26,36]$. The interaction between S-25(OH)D and iCa may be relevant in clinical practice.
SHPT was not prevalent with $\mathrm{S}-25(\mathrm{OH}) \mathrm{D} \geq 100 \mathrm{nmol} / \mathrm{l}$ and $\mathrm{iCa}$ in the upper two tertiles of reference range at 5 years, which we previously reported 2 years postoperatively [20].

Optimal S-25(OH)D levels are not established after RYGB and obesity surgery in general. Achieving S-25(OH)D $\geq$ $100 \mathrm{nmol} / 1$ may be needed to suppress SHPT more effectively in some individuals, with an aim to improve long-term bone health.

\section{Strengths and Limitations}

The main strength of this study was a large sample size with high 5-year follow-up rate and repeated measurements, providing statistical strength. Bias of primary hyperparathyroidism was minimized. The single centre study design with standard surgical and follow-up procedures strengthen internal validity, but the findings need testing in other populations. As relationships up to 5 years were the primary focus, only patients with 5-year data on S-25(OH)D and PTH were included. Prevalence of SHPT in nonattenders may be higher than observed, assuming less compliance [37]. Data on preoperative S-25(OH)D and PTH, and S-25(OH)D $\geq 100 \mathrm{nmol} / 1$ and B-ALP, during follow-up were limited. Supplemental use was self-reported. iCa determinations at the Hormone Laboratory were adjusted during the period; however, the drop in $\mathrm{iCa}$ was also found in some parallel analyses performed at the Central Laboratory, with unchanged methodology.

\section{Conclusions}

S-25(OH)D levels related inversely with PTH development and occurrence of SHPT up to 5 years after RYGB. The prevalence of SHPT was lower with S-25(OH)D thresholds $\geq$ $50 \mathrm{nmol} / 1$ and $\geq 75 \mathrm{nmol} / 1$. Some patients may need $\mathrm{S}-25(\mathrm{OH}) \mathrm{D} \geq 100 \mathrm{nmol} / \mathrm{l}$ to suppress SHPT more effectively.

Acknowledgements Open access funding provided by Oslo University \& Oslo University Hospital. Per Thorsby at the Hormon Laboratory and Solve Tjora at the Central Laboratory assisted with laboratory data, Inger Eribe and Marianne Sæter at Center for Morbid Obesity and Bariatric Surgery assisted with patient data, all located at Oslo University Hospital, Aker.

\section{Compliance with Ethical Standards}

Disclosures, Ethics and Consent The Regional Ethical Committee approved the study. All procedures performed were in accordance with the ethical standards of the institutional and national research committee and with the 1964 Helsinki declaration and its later amendments. Informed consent was obtained from all individual participants included in the study.

Conflict of interest The authors declare that they have no conflict of interest. 
Open Access This article is licensed under a Creative Commons Attribution 4.0 International License, which permits use, sharing, adaptation, distribution and reproduction in any medium or format, as long as you give appropriate credit to the original author(s) and the source, provide a link to the Creative Commons licence, and indicate if changes were made. The images or other third party material in this article are included in the article's Creative Commons licence, unless indicated otherwise in a credit line to the material. If material is not included in the article's Creative Commons licence and your intended use is not permitted by statutory regulation or exceeds the permitted use, you will need to obtain permission directly from the copyright holder. To view a copy of this licence, visit http://creativecommons.org/licenses/by/4.0/.

\section{References}

1. Mechanick JI, Kushner RF, Sugerman HJ, et al. American Association of Clinical Endocrinologists, The Obesity Society, and American Society for Metabolic \& Bariatric Surgery medical guidelines for clinical practice for the perioperative nutritional, metabolic, and nonsurgical support of the bariatric surgery patient. Obesity. 2009;17(Suppl 1):S1-S70.

2. Busetto L, Dicker D, Azran C, et al. Obesity Management Task Force of the European Association for the study of obesity released "practical recommendations for the post-bariatric surgery medical management". Obes Surg. 2018;28(7):2117-21.

3. Via MA, Mechanick JI. Nutritional and micronutrient care of bariatric surgery patients: current evidence update. Curr Obes Rep. 2017;6(3):286-96.

4. Mechanick JI, Youdim A, Jones DB, et al. Clinical practice guidelines for the perioperative nutritional, metabolic, and nonsurgical support of the bariatric surgery patient-2013 update: cosponsored by American Association of Clinical Endocrinologists, the Obesity Society, and American Society for Metabolic \& Bariatric Surgery. Surg Obes Relat Dis. 2013;9(2):159-91.

5. Parrott J, Frank L, Rabena R, et al. American Society for Metabolic and Bariatric Surgery Integrated Health Nutritional Guidelines for the surgical weight loss patient 2016 update: micronutrients. Surg Obes Relat Dis. 2017;13(5):727-41.

6. Sandvik J, Laurenius A, Naslund I, Videhult P, Wiren M, Aasheim ET. [Nordic guidelines for follow-up after obesity surgery]. Tidsskr Nor Laegeforen 2018; 138(4).

7. Ross AC, Manson JE, Abrams SA, et al. The 2011 report on dietary reference intakes for calcium and vitamin D from the Institute of Medicine: what clinicians need to know. J Clin Endocrinol Metab. 2011;96(1):53-8.

8. Holick MF, Binkley NC, Bischoff-Ferrari HA, et al. Evaluation, treatment, and prevention of vitamin D deficiency: an Endocrine Society clinical practice guideline. J Clin Endocrinol Metab. 2011;96(7):1911-30.

9. Johnson JM, Maher JW, DeMaria EJ, et al. The long-term effects of gastric bypass on vitamin D metabolism. Ann Surg. 2006;243(5): 701-4. discussion 4-5

10. Switzer NJ, Marcil G, Prasad S, et al. Long-term hypovitaminosis D and secondary hyperparathyroidism outcomes of the Roux-en-Y gastric bypass: a systematic review. Obes Rev. 2017;18(5):560-6.

11. Monaco-Ferreira DV, Leandro-Merhi VA, Aranha NC, et al. Vitamin D deficiency and paratohommonium increase in late postoperative gastric bypass in Roux-En-Y. Arq Bras Cir Dig. 2018;31(4):e1407.

12. Aaseth E, Fagerland MW, Aas AM, et al. Vitamin concentrations 5 years after gastric bypass. Eur J Clin Nutr. 2015;69(11):1249-55.
13. Risstad H, Sovik TT, Engstrom M, et al. Five-year outcomes after laparoscopic gastric bypass and laparoscopic duodenal switch in patients with body mass index of 50 to 60 : a randomized clinical trial. JAMA Surgery. 2015;150(4):352-61.

14. Karefylakis C, Naslund I, Edholm D, et al. Vitamin D status 10 years after primary gastric bypass: gravely high prevalence of hypovitaminosis D and raised PTH levels. Obes Surg. 2014;24(3): 343-8.

15. Raoof M, Naslund I, Rask E, et al. Effect of gastric bypass on bone mineral density, parathyroid hormone and vitamin D: 5 years follow-up. Obes Surg. 2016;26(5):1141-5.

16. Liu $\mathrm{C}, \mathrm{Wu} \mathrm{D}$, Zhang JF, et al. Changes in bone metabolism in morbidly obese patients after bariatric surgery: a meta-analysis. Obes Surg. 2016;26(1):91-7.

17. Svanevik M, Risstad H, Hofso D, et al. Bone turnover markers after standard and distal Roux-en-Y gastric bypass: results from a randomized controlled trial. Obes Surg. 2019;29:2886.

18. Yu EW. Bone metabolism after bariatric surgery. J Bone Miner Res. 2014;29(7):1507-18.

19. Lindeman KG, Greenblatt LB, Rourke C, et al. Longitudinal 5-year evaluation of bone density and microarchitecture after Roux-en-Y gastric bypass surgery. J Clin Endocrinol Metab. 2018;103(11): 4104-12.

20. Hewitt S, Aasheim ET, Sovik TT, et al. Relationships of serum 25hydroxyvitamin $\mathrm{D}$, ionized calcium and parathyroid hormone after obesity surgery. Clin Endocrinol. 2018;88(3):372-9.

21. Blom-Hogestol IK, Hewitt S, Chahal-Kummen M, et al. Bone metabolism, bone mineral density and low-energy fractures 10 years after Roux-en-Y gastric bypass. Bone. 2019;127:436-45.

22. Gagnon C, Schafer AL. Bone health after bariatric surgery. JBMR plus. 2018;2(3):121-33.

23. Hewitt S, Sovik TT, Aasheim ET, et al. Secondary hyperparathyroidism, vitamin D sufficiency, and serum calcium 5 years after gastric bypass and duodenal switch. Obes Surg. 2013;23(3):384-90.

24. Chakhtoura MT, Nakhoul NN, Shawwa K, et al. Hypovitaminosis $\mathrm{D}$ in bariatric surgery: a systematic review of observational studies. Metabolism. 2016;65(4):574-85.

25. Peterson LA, Zeng X, Caufield-Noll CP, et al. Vitamin D status and supplementation before and after bariatric surgery: a comprehensive literature review. Surg Obes Relat Dis. 2016;12(3):693-702.

26. Rosen CJ, Abrams SA, Aloia JF, et al. IOM committee members respond to Endocrine Society vitamin D guideline. J Clin Endocrinol Metab. 2012;97(4):1146-52.

27. von Elm E, Altman DG, Egger M, et al. The strengthening the reporting of observational studies in epidemiology (STROBE) statement: guidelines for reporting observational studies. Lancet. 2007;370(9596):1453-7.

28. Gastrointestinal surgery for severe obesity: National Institutes of Health Consensus Development Conference Statement. Am J Clin Nutr. 1992;55(2 Suppl):615s-9s.

29. Sovik TT, Taha O, Aasheim ET, et al. Randomized clinical trial of laparoscopic gastric bypass versus laparoscopic duodenal switch for superobesity. Br J Surg. 2010;97(2):160-6.

30. Salte OB, Sovik TT, Risstad H, Skattum J, Blom-Hogestol IK, Eribe IEL, et al. Bariatric surgery at Oslo University Hospital 2004-14. Tidsskr Nor Laegeforen 2019; 139(10).

31. Schafer AL, Weaver CM, Black DM, et al. Intestinal calcium absorption decreases dramatically after gastric bypass surgery despite optimization of vitamin D status. J Bone Miner Res. 2015;30(8):1377-85.

32. Riedt CS, Brolin RE, Sherrell RM, et al. True fractional calcium absorption is decreased after Roux-en-Y gastric bypass surgery. Obesity. 2006;14(11):1940-8.

33. Kontogeorgos G, Trimpou P, Laine CM, et al. Normocalcaemic, vitamin D-sufficient hyperparathyroidism - high prevalence and low morbidity in the general population: a long-term follow-up 
study, the WHO MONICA project, Gothenburg, Sweden. Clin Endocrinol. 2015;83(2):277-84.

34. Bollerslev J, Schalin-Jantti C, Rejnmark L, et al. Management of endocrine disease: unmet therapeutic, educational and scientific needs in parathyroid disorders. Eur J Endocrinol. 2019;181(3):P1-p19.

35. Muschitz C, Kocijan R, Haschka J, et al. The impact of vitamin D, calcium, protein supplementation, and physical exercise on bone metabolism after bariatric surgery: the BABS study. J Bone Miner Res. 2016;31(3):672-82.
36. Heaney RP. What is vitamin D insufficiency? And does it matter? Calcif Tissue Int. 2013;92(2):177-83.

37. Harper J, Madan AK, Ternovits CA, et al. What happens to patients who do not follow-up after bariatric surgery? Am Surg. 2007;73(2): $181-4$.

Publisher's Note Springer Nature remains neutral with regard to jurisdictional claims in published maps and institutional affiliations. 